Recibido: 12 marzo 2020 | Aceptado: 25 octubre 2020 | Publicado: 23 diciembre 2020

Cita: Aguilar Ruiz, M. (2020). Reseña de M. a Carme Jonyent Figueras y Pere Comellas Casanova: Antropología lingüística.

Madrid: Editorial Síntesis (2019), 235 páginas. ISBN: 978-84-9171-431-6. Normas, 10(1), 93-100. doi:

http://dx.doi.org/10.7203/Normas.v10i1.18148

\title{
Reseña de M. ․ Carme Jonyent Figueras y Pere Comellas Casanova: Antropología lingüística. Madrid: Editorial Síntesis (2019), 235 páginas. ISBN: 978-84-9171-431-6.
}

\author{
Manuel José Aguilar Ruiz
}

Universitat de València

El objetivo que pretende el breve manual aquí reseñado, como indica su misma «Introducción», es el de ofrecer una aproximación a la disciplina que conocemos como antropología lingüística con la que, partiendo de los procedimientos y métodos clásicos de estudio de esta disciplina, se entienda cómo es posible establecer una relación entre lenguas y culturas (bajo concepciones tradicionales o, según las perspectivas más actuales, entre lo lingüístico y lo extralingüístico). De este modo, el libro pretende ser «una introducción al fascinante mundo de las lenguas y sus relaciones con las culturas, tan distintas y al mismo tiempo tan iguales en la medida en que se trata de manifestaciones de una misma cara, la humana. Pretende también sumarse a la defensa de la diversidad» (pág. 10).

La obra consta de seis capítulos, como se verá seguidamente.

1. El capítulo primero, «Caracterización e historia de la antropología lingüística», consiste en una introducción general a la antropología lingüística como disciplina, para lo cual introduce primeramente definiciones y conceptos clave desde diversas perspectivas y autores (Boas, Duranti, Foley, Rossi, Ottenheimer, Malinowski, Tylor, etc.); después analiza una serie de cuestiones clave para el marco teórico y de estudio de esta disciplina, como la relación entre lenguas y culturas, qué entiende la antropología por cultura, la relación de la antropología lingüística, en situación de independencia o dependencia, respecto a otras disciplinas, etc., para terminar reflexionando sobre las lenguas como elementos culturales.

A continuación ofrece una breve historia de la disciplina, desde los principales indicios señalados en la Antigüedad y el Renacimiento hasta llegar, con mayor detenimiento, a Humboldt y otros autores del siglo XIX y, a partir de aquí, focalizarse en los autores del siglo $\mathrm{XX}$ y en lo que puede contemplarse como el nacimiento y configuración de esta disciplina como tal, comenzando por la escuela boasiana y sus seguidores (Boas, Sapir, Kroeber) y autores posteriores (como Whorf, Hoijer, Swadesh, Haas, Greenberg, Malinowski, etc.), hasta analizar tendencias actuales como la etnografía de la comunicación o la antropología cognitiva. Seguidamente, profundiza en la conocida «hipótesis Sapir-Whorf» o relatividad lingüística, 
tanto en su versión determinista o fuerte como en la relativista o débil, ofreciendo también diversas formulaciones derivadas, como la «hipótesis Boas-Jakobson» de Deutscher o la «hipótesis del pensar para hablar» de Slobon, además de críticas a dicha hipótesis, como las realizadas por Lenneberg, Greenberg, Lucy, Gumperz, Levinson o Moreno Cabrera.

2. En el capítulo segundo, «Bases, procedimientos y métodos de la antropología lingüística», se abordan los conceptos, mecanismos y procedimientos metodológicos más relevantes empleados en esta disciplina. Se ocupa, en primer lugar, del concepto de la categorización, y contrapone diversos puntos de vista sobre los procedimientos cognitivos con los que categorizamos el mundo planteados por varios autores (Whorf, Leach, Rosch, Wittgenstein), prestando especial atención a la teoría de los prototipos y a los distintos modos en los que las culturas pueden categorizar el mundo (por ejemplo, cómo se ha categorizado una misma realidad extralingüística como los nombres de parentesco tío y tía en español, suajili ${ }^{1}, \operatorname{sami}^{2}$ y latín).

Se ocupa, a continuación, de los diversos procedimientos para la organización del léxico, especialmente de las taxonomías (por ejemplo, describe algunas taxonomías del reino animal del idioma bribri $^{3}$ ), pero también de las distintas formas de partonomías y las relaciones simétricas de semejanza y contraste etiquetadas semánticamente como sinonimia y antonimia. El siguiente mecanismo estudiado es el análisis componencial para campos semánticos muy estructurados y limitados, con el ejemplo del llamativo caso del sistema pronominal del hanunóo ${ }^{4}, y$ ofrece, a su vez, distintas críticas que suelen achacarse a este procedimiento metodológico (por parte de autores como Pike, Harris, Schneider, Reynoso, Atchinson, etc.). De los restantes mecanismos que emplea la antropología lingüística analizados en el capítulo, podríamos mencionar también el concepto de corte estructuralista de marca o término marcado (con ilustrativos ejemplos sobre la marcación de la categoría de género) y el trabajo de campo (o labor de obtención de datos, con la enumeración de los distintos métodos, problemas y aspectos éticos que este trabajo conlleva).

3. Por otro lado, el capítulo tercero, «La lengua y las personas», parte del marcado carácter antropocéntrico del lenguaje humano para estudiar la enorme diversidad que representa la relación entre lenguas y culturas. Para ello, se centra en tres sistemas básicos y universales de la lengua: los pronombres personales, los nombres de parentesco para denominar a los miembros de la familia y los antropónimos para nombrar a los individuos.

3.1. Respecto a los pronombres personales, se estudian, desde diferentes lenguas, las distintas categorías que estos suelen reflejar (persona, número, género, función semántica y marca de estatus), con lo que es posible apreciar la gran diversidad en la concepción lingüística de estos. Así, para la categoría persona se analizan, por ejemplo, los pronombres logofóricos (empleados para distinguir a la tercera persona que participa en un acto discursivo de la que no lo hace), con ejemplos del ewé ${ }^{5} \mathrm{y}$ las lenguas angas ${ }^{6}$ (del «cinturón logofórico» africano), o las distintas formas

\footnotetext{
${ }^{1}$ Lengua nigerocongolesa hablada en distintos países del África oriental.

${ }^{2}$ Conjunto lingüístico de la familia urálica, hablado en Laponia.

${ }^{3}$ Lengua chibcha hablada en Costa Rica.

${ }^{4}$ Lengua malayo-polinesia hablada en la isla de Mindoro, en Filipinas.

${ }^{5}$ Lengua nigerocongolesa hablada en Benín, Ghana y Togo.

${ }^{6}$ Conjunto lingüístico afroasiático de la familia chádica.
} 
de plurales inclusivos y exclusivos en lenguas como el uradhi ${ }^{7}$, el motuna ${ }^{8}$ y el yauré ${ }^{9}$. Resultan también llamativos los casos del tigré ${ }^{10}$, que presenta oposición de género en la segunda persona del singular, o del korana ${ }^{11}$, que cuenta con un complejo sistema pronominal con tres géneros, distinción entre plural inclusivo y exclusivo y número dual. Además, la gran diversidad de estrategias que han desarrollado las lenguas del mundo para marcar el estatus entre los interlocutores del acto discursivo se refleja con ejemplos de otras lenguas (zapoteco de San Lucas $^{12}$, nepalí, tamil ${ }^{13}$, italiano, alemán, amhárico, polaco, portugués europeo, worora ${ }^{14}$, blackfoot ${ }^{15}$, etc.).

3.2. La rica diversidad lingüística queda también manifiesta en los distintos procedimientos para denominar a los familiares en los sistemas de parentesco. Así, vemos cómo el euskera cuenta con cuatro términos distintos para designar la relación de 'hermandad' (ahizpa, anaia, arreba y neba), ya que tiene en cuenta, además del sexo del referente, el sexo del ego (es decir, la persona de referencia o anclaje a partir de la que se define el parentesco). Reporta seguidamente la discusión acerca de si la familia es una realidad biológica o una estrategia cultural, y analiza a través de distintas propuestas (de estudiosos como Kroeber, Morgan, Lounsbury, Foley, Gould, Romney y Kronenfeld) diferentes lenguas del mundo (tamil, tahitiano, sami, hawaiano, lenguas inuit, sudanés, omaha ${ }^{16}$, etc.), para terminar reflexionando sobre la categorización lingüística de la estratificación social y sexual y sobre los usos lingüísticos sexistas y discriminatorios (si asumimos las ideas, de raíces relativistas, de que cambiando determinados usos lingüísticos se superaría el sexismo y la discriminación en la sociedad, y la posibilidad de que las gramáticas sean susceptibles de ser manipuladas de manera consciente por parte de los hablantes, de modo que cambiando la lengua cambie la sociedad).

3.4. Por otra parte, este tercer capítulo termina exponiendo la importancia de la diversidad antropológica de los antropónimos para nombrar personas, y explica algunas pautas a la hora de escogerlos, tales como homenajes a personas relevantes en la historia de una cultura, como la cristiana o la islámica (repitiendo nombres de pila del tipo María, Jesús, Mohamed, Youssef, Omar), como homenaje a ancestros familiares que los portaron antes (originando incluso series intergeneracionales), e incluso la imposición del nombre en base al día del nacimiento (como, por ejemplo, Kofi o Mgbeke en igbo ${ }^{17}$ ) $\mathrm{u}$ otros factores, o la existencia de un segundo nombre de uso restringido, además del nombre público (ante la creencia de que este nombre secreto permite mantenerse a salvo de actos mágicos), la posibilidad que tiene una persona de ser renombrada (como signo de cambio de identidad o para despistar a los malos espíritus, como entre el pueblo ainu $\left.{ }^{18}\right)$. Observa también cómo muchos países que emprendieron un proceso de descolonización han tendido a recuperar su sistema onomástico tradicional anterior a la presencia colonial, y

\footnotetext{
${ }^{7}$ Lengua aborigen australiana del grupo pama-nyunga.

${ }^{8}$ Lengua papúa oriental hablada en Nueva Guinea.

${ }^{9}$ Lengua nigerocongolesa del grupo mandé, hablada en Costa de Marfil.

${ }^{10}$ Lengua semítica hablada en Eritrea y Sudán.

${ }^{11}$ Lengua joisana del Kalahari.

12 Lengua amerindia mesoamericana de la rama zapoteca, hablada en el estado mexicano de Oaxaca.

${ }^{13}$ Lengua dravídica hablada en el estado indio de Tamil Nadu y en Sri Lanka.

14 Lengua aborigen australiana.

15 Lengua amerindia algonquina.

${ }^{16}$ Lengua amerindia de la familia siux, hablada en las reservas indias de los estados de Nebraska y Oklahoma.

${ }^{17}$ Lengua nigerocongolesa hablada principalmente en Guinea Ecuatorial y Nigeria.

${ }^{18}$ Grupo étnico de las islas septentrionales de Japón.
} 
reflexiona, apoyándose en estadísticas y gráficos evolutivos de nombres propios puestos en Guipúzcoa desde la década de 1930, hasta qué punto somos libres, en las culturas occidentales, a la hora de nominar a los individuos nacidos, o cómo estamos afectados por «modas».

4. El capítulo cuarto, «Universales lingüísticos y cultura», analiza algunos campos referenciales considerados idóneos para evaluar su universalidad o dependencia de las distintas culturas que han sido campos de estudio tradicionales de la disciplina (la posible existencia de un léxico básico universal, los conceptos de 'posesión', 'espacio' y 'tiempo', y los términos para los numerales y los colores).

4.1. Así, entra primeramente en el debate sobre la existencia de un vocabulario básico de naturaleza universal (esto es, un conjunto de términos referentes a elementos comunes a todos los humanos, como los somatismos o actividades básicas del tipo 'comer', 'dormir' o 'caminar', que se encuentran en todas las lenguas y que, por lo tanto, resultan más resistentes al fenómeno del préstamo léxico). Tiene en cuenta a los defensores de esta teoría (Swadesh, Goddard, Wierzbicka, etc.) y a sus retractores (Dixon, Campbell, Posner y otros).

4.2. A continuación, descubrimos cómo difiere el concepto de 'posesión' en distintas lenguas del mundo, de modo que se pueden encontrar diversas concepciones y estructuras gramaticales para determinar esta propiedad. Por ejemplo, vemos cómo en lengua maa ${ }^{19}$ hay sustantivos que admiten marcas gramaticales de posesión (como niño) frente a otros que tienen incorporada la noción de imposesibilidad (en nombres como río, montaña, tierra, etc.), o se aclaran los conceptos de posesión inalienable (es decir, intrínseca, como en los somatismos) o posesión alienable (esto es, circunstancial, mercantilizable, en sustantivos como serían casa, coche, etc.) que presentan algunas lenguas (motu ${ }^{20}$, fidyiano, panare ${ }^{21}$, bambara ${ }^{22}$, etc.), con las que se evidencian los factores culturales con los que se determina la pertenencia de un referente a una u otra categoría (por ejemplo, en inuktitut ${ }^{23}$ un cuchillo es una posesión inalienable, como si se tratase de una parte del cuerpo). Se acaban analizando distintas estrategias gramaticales para expresar la posesión presentes en lenguas como el español, catalán, indonesio, ruso, dyirbal ${ }^{24}$, hebreo, karbi $^{25}$, fiyiano, etc.

4.3. Los numerales vuelven a evidenciar la enorme diversidad lingüística ante un único hecho: numerar. Así, se analizan en primer lugar distintos sistemas de numeración (quinarios, decimales, vigesimales, binarios y otros con distinta base) y recursos para crear numerales compuestos a partir de las bases (adición, multiplicación, sustracción, etc.) en una enorme cantidad de lenguas (euskera, camboyano, francés, yoruba ${ }^{26}$, haruai ${ }^{27}, \operatorname{tarasco}^{28}$, latín, bubi ${ }^{29}$, galés, etc. Como curiosidad, observamos que resulta habitual que muchas lenguas (por ejemplo, amerindias) empleen el mismo término para las nociones de 'cinco' y 'mano', por un lado, o de 'veinte' y 'persona', por otro, al ser el cuerpo la primera calculadora natural humana

\footnotetext{
${ }^{19}$ Lengua de la familia nilótica hablada en Kenia y Tanzania.

${ }^{20}$ Lengua malayo-polinesia hablada en Papúa Nueva Guinea.

${ }^{21}$ Lengua caribe hablada en los estados venezolanos de Amazonas y Bolívar.

22 Nigerocongolesa del grupo mandingá hablada principalmente en Burkina Faso, Costa de Marfil y Mali.

${ }^{23}$ Conjunto de variedades esquimo-aleutianas habladas en las zonas árticas de Norteamérica.

${ }^{24}$ Lengua aborigen australiana del grupo pama-ñungana.

${ }^{25}$ Lenguas tibetano-birmanas habladas en el noroeste de la India, principalmente en los estados de Assam y Meghalaya.

${ }^{26}$ Conjunto lingüístico de la familia nigerocongolesa, hablado en el África Occidental

${ }^{27}$ Lengua papúa de la rama piawi, hablada en Nueva Guinea.

${ }^{28}$ Lengua amerindia aislada mesoamericana, hablada en México.

${ }^{29}$ Lengua nigerocongolesa hablada en la isla de Bioko, en Guinea Ecuatorial.
} 
(recordemos, igualmente, que la voz latina digitus se refiere tanto a 'dedo' como a 'dígito', 'número').

Se discute seguidamente hasta qué punto los numerales son productos culturales, analizando el llamativo fenómeno de transferencia léxica que comparten numerosas lenguas (romaní de los gitanos alemanes, tagalo, hausa ${ }^{30}$, cebuano $^{31}$, maisin $^{32}$, garífuna ${ }^{33}$, pangasino $^{34}$, abjaso ${ }^{35}$, yoruba, etc.), y aportando casos de sistemas numerales extremadamente simples (haruai, mundurucú ${ }^{36}$, panobo ${ }^{37}$, pirahã $\tilde{a}^{38}$, etc.), al parecer característicos de sociedades de cazadoresrecolectores. Seguidamente, se ratifica el hecho de que la calculadora natural para numerar ha sido el cuerpo humano, ya que en él tuvieron su origen los distintos sistemas numerales, que conservan entre sus términos las bases léxicas de dedo, mano, pie y otros somatismos (como se aprecia en latín, jíbaro ${ }^{39}$, urubú-kaapur ${ }^{40}$, baniwa ${ }^{41}$, mundurucú, mian $^{42}$, haruai, diversas lenguas amerindias, etc.).

4.4. A continuación se analiza pormenorizadamente el carácter universal o particular de las concepciones de 'espacio' y 'tiempo' en su reflejo lingüístico y sus posibles consecuencias cognitivas. Así, tras establecer las posibles marcas de referencia espaciales que pueden aparecer codificadas lingüísticamente, se analiza su empleo por parte de varias lenguas del mundo (español, guugu yimithir ${ }^{43}$, tzetzal de Tenejapa ${ }^{44}$, etc.), para continuar estudiando la categoría 'tiempo' y cómo suele esta solaparse con la de 'espacio' (con ejemplos del español, inglés, búlgaro, udmurto ${ }^{45}$, abjasio, chino, etc., extraídos de Haspelmatch), siendo generalmente las expresiones de tiempo (de naturaleza más abstracta) derivadas secundarias de las expresiones lingüísticas espaciales (normalmente de carácter más primario por su percepción más clara y directa), fenómeno que resulta, al parecer, una proyección de naturaleza universal.

4.5. Por último, otro de los campos clásicos de investigación antropolingüística de los que se ocupa este capítulo es la relación entre los términos de los colores y la cultura, esto es, de la percepción del color y el uso lingüístico de este, ya que las diferencias de las caracterizaciones léxicas de los colores entre las lenguas ha sido una cuestión clave para las concepciones relativistas y deterministas del lenguaje. Así pues, se analizan distintas perspectivas desde las que abordar este tema (la hipótesis de Berlin y Kay, el proyecto de investigación World Color Survey, los estudios de Roberson, Davies y Davidoff o de Kay y Regier y otros experimentos recientes), para terminar estudiando los valores culturales de los colores, como las connotaciones compartidas por algunos de ellos en muchas culturas (el rojo, color de la sangre, para la expresión de la ira, el peligro o la alarma, o el blanco y el negro, relacionados con la

\footnotetext{
${ }^{30}$ Lengua afroasiática del grupo chádico, hablada en Níger y Nigeria.

${ }^{31}$ Lengua malayo-polinesia hablada en Filipinas.

${ }^{32}$ Lengua austronesia hablada en Papúa Nueva Guinea.

${ }_{33}$ Lengua arahuaca hablada por la costa caribe de Centroamérica.

${ }^{34}$ Lengua malayo-polinesia hablada en Filipinas.

${ }^{35}$ Lengua de la familia caucásica septentrional, hablada en el Cáucaso occidental.

${ }^{36}$ Lengua tupí hablada en Brasil.

${ }^{37}$ Lengua extinta del grupo pano, que fue hablada en Perú.

38 Lengua aislada hablada en Brasil.

${ }^{39}$ Conjunto de lenguas aisladas hablado en Ecuador y Perú.

${ }^{40}$ Lengua tupí-guaraní hablada principalmente en Brasil.

${ }^{41}$ Conjunto lingüístico de la familia arahuaca, hablado en zonas de Brasil, Colombia y Venezuela.

${ }^{42}$ Lengua de la familia hmong-mien hablada en el sureste asiático.

${ }^{43}$ Aborigen australiana de la familia pama-nyungan.

${ }^{44}$ Lengua mayense hablada en el estado mexicano de Chiapas.

${ }^{45}$ Lengua fino-ugria hablada en Rusia.
} 
virtud y la pureza o lo lúgubre o negativo) y presentes frecuentemente en determinadas expresiones idiomáticas culturalizadas (en español, por ejemplo, estar verde de envidia o poner negro a alguien).

5. «Las ideologías lingüísticas» es el título del capítulo quinto, en el que, tras establecer las definiciones del concepto de ideología lingüística planteadas por autores como Rumsey, Silverstein, Kroskrity, Bourdieu o Woolard, además de su base de interés interdisciplinar, se ofrecen detalladamente descripciones de las tres líneas tradicionales de investigación que se ocupan de las ideologías lingüísticas, según Woolard. Por ejemplo, entre otras muchas cuestiones, se aborda la relación entre ideología lingüística y estructuras de las lenguas, una perspectiva más pragmática en la que las formas honoríficas, el lenguaje inclusivo o el lenguaje políticamente correcto suponen campos de estudio realmente rentables. También trata de desmentir prejuicios lingüísticos como la presunta existencia de lenguas superiores a otras o más aptas para determinados campos (el presunto primitivismo y tosquedad de las lenguas aborígenes australianas, la carencia de formas de futuro entre ciertas lenguas africanas, por lo que sus hablantes no lo concebirían, o la idoneidad del alemán para conceptos abstractos filosóficos).

El capítulo termina realizando una revisión de la teoría de la acomodación de Giles, esto es, la tendencia del hablante a adaptar su forma de hablar (convergiendo o divergiendo respecto a su interlocutor), reportándose situaciones que van desde acomodaciones asimétricas en las que el hablante de una lengua minorizada adopta una lengua mayorizada si su interlocutor es hablante de esta última hasta casos de multilingüismo no conflictivo, en ocasiones sorprendente, como la zona amazónica fronteriza entre Colombia y Brasil o el caso de Warruwi, una pequeña comunidad (de no más de cuatrocientas personas) en una isla del norte de Australia en la que conviven hasta nueve lenguas de seis familias distintas.

6. El sexto y último capítulo, «Las lenguas amenazadas y el futuro de la diversidad», se ocupa del preocupante problema de la desaparición de lenguas, partiendo de la observación de que si bien el conocimiento global de la diversidad lingüística nunca ha sido tan considerable como lo es en la actualidad, parece que nunca esta diversidad lingüística ha estado tan amenazada. De hecho, pese a las dificultades para definir el concepto de lengua (ya que los criterios tradicionales de intercomprensión, tradición y conciencia de los hablantes resultan enormemente problemáticos), se observa un enorme desequilibrio en la distribución del número de hablantes de las lenguas del mundo y del territorio geográfico en el que se hablan, pues el $96 \%$ de las personas del planeta hablan un $4 \%$ de las lenguas existentes, tal y como puntualizan los autores del manual.

Se aborda primeramente el fenómeno de la extinción de las lenguas, observando las razones y procesos por los que las lenguas van desapareciendo. Para ello emplea algunos conceptos del lingüista valenciano Aracil i Boned (interposición, bilingüismo unilateral y minorización) y el modelo gaélico-arvanitika de Sasse, entre otros recursos. Seguidamente, analiza las ventajas e inconvenientes de los diversos modelos para la graduación y escalación de la desaparición de las lenguas, como el generacional de Fishman (GIDS), el multifactorial de la Unesco, el de Krauss, el EGIDS de Lewis y Simons (que es una ampliación de la GIDS de Fishman, empleado por Ethnologue $^{46}$ ), el de Huiying Lee y Van Way (empleado por el Catalogue of Endangered

\footnotetext{
${ }^{46}$ En <https://www.ethnologue.com>.
} 
Languages, ELCat ${ }^{47}$ ), etc., para explicar a continuación la tipología de los hablantes de lenguas recesivas propuesta por Grinevald y Bert (divisibles en hablantes fluidos, semihablantes, hablantes parciales, recordadores, hablantes fantasma, neohablantes y últimos hablantes). El capítulo termina observando algunos factores que amenazan las lenguas, desde el marco estadonación hasta los diversos tipos de procedimientos de coerción, en los que se enmarcan las prácticas escolares represivas y delatorias (con diversos castigos físicos y psicológicos, como el symbole francés o àccipe italiano), la represión del uso de una lengua en el puesto de trabajo e incluso la enclosure (el desplazamiento y confinamiento de poblaciones en reservas geográficas determinadas, como en los casos de los pueblos nativos americanos o las deportaciones estalinistas de la antigua URSS).

7. Por último, la nutrida bibliografía ostenta (como manifiestan los propios autores) un claro compromiso ecológico y económico al ofrecer impresas las referencias bibliográficas mínimas y unas dataciones básicas para el reconocimiento de las obras citadas y recomendadas, vinculando a la web de la Editorial Síntesis para que los lectores interesados puedan acceder y descargar en formato PDF la versión íntegra y extendida de la bibliografía ${ }^{48}$. La propia editorial facilita en su web ${ }^{49}$ un PDF descargable de parte de la obra (consistente en el índice y una muestra del capítulo segundo ${ }^{50}$.

8. Como valoración del manual que aquí nos ocupa, hemos de anotar que supone una excelente obra introductoria a la antropología lingüística como disciplina. Aunque el manual carece de un capítulo final donde se expongan conclusiones generales sobre lo expuesto a lo largo de la obra, cada capítulo ofrece un breve resumen en el que se ponen de manifiesto las principales líneas analizadas. El detallado índice actúa también como guía bastante útil entre la diversidad de los temas tratados. Sin duda, la lectura y estudio de este manual resulta altamente recomendable para aquellos lectores que desean adentrarse en la antropología lingüística.

\footnotetext{
${ }^{47}$ En $<$ http://endangeredlanguages.com>.

${ }^{48}$ En concreto, en el sitio web:

$<$ https://www.sintesis.com/data/files/uploads/Biblioweb\%20Antropologia\%20linguistica(1).pdf>. ${ }^{49} \mathrm{En}$

<https://www.sintesis.com/claves\%20de\%20la\%20ling\%C3\%BC\%C3\%ADstica200/antropolog\%C3\%ADa\%20ling\%C3\%BC\%C3\%ADstica-ebook-2765.html>.

${ }^{50}$ En la página <https://www.sintesis.com/data/indices/9788491714316.pdf>.
} 
